\title{
Setiap Modul merupakan Submodul dari Suatu Modul Bersih
}

\author{
Kartika Sari ${ }^{1}$, Indah Emilia Wijayanti ${ }^{2}$ \\ 1)Jurusan Matematika,Fakultas MIPA, Universitas Udayana \\ Kampus Bukit Jimbaran, Badung, Bali \\ Email: sari_kaartika@yahoo.co.id \\ 2) Program Studi Pascasarjana Fakultas MIPA, Universitas Gadjah Mada \\ Sekip Utara Kotak Pos: BLS 21, Yogyakarta 55281 \\ Email: ind_wijayanti@yahoo.com
}

\begin{abstract}
ABSTRAK
Diberikan ring $\mathrm{R}$ dengan elemen satuan. Suatu ring $\mathrm{R}$ dikatakan bersih apabila setiap elemennya dapat dinyatakan dalam bentuk jumlahan suatu elemen unit dan suatu elemen idempoten dari ring $R$, sedangkan suatu $R$ modul $\mathrm{M}$ dikatakan bersih apabila ring endomorfismanya merupakan ring bersih. Berdasarkan sifat bahwa modul kontinu merupakan modul bersih, dalam penelitian ini ditunjukkan bahwa setiap modul merupakan submodul dari suatu modul bersih..
\end{abstract}

Kata kunci: ring bersih, submodul, modul bersih

\section{ABSTRACT}

Given any ring $R$ with unity. A ring $R$ is called clean if each element of $R$ is the sum of a unit and an idempotent, while an $R$-module $M$ is called clean if its endomorphism ring is clean. Based on the property that every continuous modules is clean, in this study, it is shown that every module is a submodule of a clean module.

Keywords:clean ring, submodule, clean module

\section{Pendahuluan}

Pada keseluruhan tulisan ini, ring yang digunakan merupakan ring dengan elemen satuan, dan yang dimaksud modul adalah modul kanan, sedangkan notasi $U(S)$ dimaksudkan grup yang elemen-elemennya merupakan elemen unit dari suatu ring S.Selanjutnya, jika diberikan himpunan $A$ dan $M$, suatu fungsi $g: A \rightarrow M$ dan suatu himpunan tak kosong $A^{\prime} \subseteq A$, maka notasi $\left.g\right|_{A^{\prime}}$ dimaksudkan pembatasan fungsi $g$ pada himpunan $A^{\prime}$ yaitu fungsi yang memetakan himpunan $A^{\prime}$ ke himpunan $g\left(A^{\prime}\right) \subseteq M$. Lebih lanjut lagi, himpunan semua bilangan bulat, bilangan rasional dan bilangan bulat modulo $n$ secara berturut-turut dinotasikan dengan $\mathrm{Z}, \mathrm{Q}$ dan $Z_{n}$.

Nicholson (1977) dalam Nicholson dan Zhou [6] memberikan definisi bahwa suatu ring $R$ dikatakan ring bersih apabila setiap elemen dari ring $R$ merupakan elemen bersih, sedangkan suatu elemen dalam suatu ring $\mathrm{R}$ dikatakan bersih apabila dapat dinyatakan sebagai hasil penjumlahan suatu elemen idempoten dan suatu elemen unit dari ring R. Camillo et.al.[1] memberikan definisi bahwa suatu modul atas ring $\mathrm{R}$ dikatakan bersih apabila ring endomorfisma dari modul tersebut merupakan ring bersih.

Diberikan ring $R, R$-modul $M$ dan aksioma-aksioma: (C1) Setiap submodul di $M$ esensial dalam suatu suku jumlah langsung di $M$, (C2) Setiap submodul dari $M$ yang isomorfis dengansuatu suku jumlah langsung dari $M$ juga merupakan suku jumlah langsung dari M, (C3) Jika A dan B keduanya merupakan suku jumlah langsung dari $\mathrm{M}$ dan $A \cap B=\{0\}$ maka $A \oplus B$ juga merupakan suku jumlah langsung dari M. Suatu modul M dikatakan kontinu apabila memenuhi aksioma-aksioma (C1) dan (C2), sedangkan suatu modul M yang memenuhi aksioma-aksioma (C1) dan (C3) dinamakan modul quasi-kontinu (Mohamed dan Muller, [5]). Camillo et.al.[1] menunjukkan bahwa setiap modul kontinu merupakan modul bersih. Lam [4] 
menunjukkan bahwa setiap modul quasi injektif merupakan modul kontinu. Di lain pihak, terdapat kenyataan bahwa setiap modul injektif merupakan modul quasi-injektif dan sebarang modul dapat disisipkan ke dalam suatu modul injektif. Berdasarkan sifat ini, dapat ditunjukkan bahwa sebarang modul dapat disisipkan ke dalam suatu modul bersih sebagai submodul. Dengan kata lain, setiap modul merupakan submodul dari suatu modul bersih, yang merupakan hasil dari penelitian ini.

Hasil ini juga telah diperoleh Sari,[7], akan tetapi melalui cara yang sedikit berbeda. Sari, [7] memperoleh hasil ini dengan menggunakan sifat bahwa setiap modul merupakan submodul dari modul injektif (Hazewinkel et.al., [3], dan setiap modul injektif-murni merupakan modul bersih (Camillo et. al., [1]).

Berikut ini diberikan beberapa konsep yang mendasari penelitian ini.

Definisi 1. Diberikan ring $R$ dan $R$-modul $M$. Modul $M$ dikatakan modul injektif apabila untuk setiap $R$-modul $A$ dan $B$ dengan $A$ submodul dari $B$ dan untuk setiap homomorfisma $f: A \rightarrow M$ terdapat homomorfisma $g: B \rightarrow M$ dengansifat $\left.g\right|_{A}=f$. Dengankata lain terdapat homomorfisma g yang memperluas f.(Hazewinkelet.al,[3])

Contoh 2. (a) Modul nol merupakan modul injektif. (b) Setiap ruang vektor atas lapangan F merupakan modul injektif.

Pada kenyataannya, tidak mudah menunjukkan suatu modul merupakan modul injektif dengan menggunakan Definisi 1. Berikut diberikan syarat perlu dan syarat cukup suatu modul merupakan modul injektif, yang sering dikenal sebagai Kriteria Baer.

Teorema 3. (Kriteria Baer) (Hazewinkelet.al., [3]) Suatu R-modul M injektif jika dan hanya jika untuk setiap ideal kanan Idi $R$, setiap homomorfisma $\alpha: I \rightarrow M$ dapat diperluas menjadi homomorfisme $\beta: R \rightarrow M$.

Dengan menggunakan Kriteria Baer, berikut diberikan contoh modul injektif lainnya.

\section{Contoh 4.}

Diperhatikan bahwa ideal-ideal dari ring bilangan bulat Z berbentuk $n \mathrm{Z}, n \in \mathrm{Z}$. Oleh karena itu, terdapat pemetaan inklusi $h: n Z \rightarrow Z$. Diberikan sebarang homomorfisma $f: n Z \rightarrow Q$, maka terdapat $q \in \mathrm{Q}$ yang memenuhi $f(n)=q$. Lebih lanjut lagi, didefinisikan suatu pengaitan $g: Z \rightarrow Q$ dengan $g(z)=z \frac{q}{n}$, maka $g$ terdefinisi dengan baik dan merupakan suatu homomorfisma. Kemudian, untuk setiap $n z \in n Z$, berlaku

$$
\begin{aligned}
& f(n z)=f(n) z=q(1) z \\
& =q\left(\frac{n}{n}\right) z=\frac{q}{n} n z=g(1) n z \\
& =g(n z)=(g \circ h)(n z)
\end{aligned}
$$

Dari sini diperoleh, $g$ memperluas $f$.Dengan kata lain Z-modul Q injektif.

Selanjutnya, diberikan contoh $Z$-modul yang tidak injektif.

\section{Contoh 5.}

Salah satu ideal dari ring $\mathrm{Z}$ adalah 2Z. Homomorfisma $f: 2 \mathrm{Z} \rightarrow \mathrm{Z}$ didefinisikan sebagai $f(2 z)=z$ untuk setiap $z \in \mathrm{Z}$. Andaikan terdapat homomorfisma $g: Z \rightarrow Z$ yang memperluas $f$, maka

$$
\begin{aligned}
& 1=f(2.1)=f(2)=(g \circ h)(2) \\
& =g(2)=g(1) 2
\end{aligned}
$$

dengan $h$ pemetaan inklusi dari $2 \mathrm{Z}$ ke $Z$.

Kontradiksi dengan $g: Z \rightarrow Z$. Jadi seharusnya, homomorfisma $f$ tidak dapat diperluas. Dengan kata lain Z-modul Z bukan modul injektif. 
Perhatikan bahwa $Z$-modul $Z$ yang bukan modul injektif merupakan submodul dari $Z$-modul $Q$ yang merupakan modul injektif. Dengan kata lain, $Z$-modul $Z$ dapat disisipkan ke dalam $Z$ modul $Q$ sebagai submodul. Sehubungan dengan hal tersebut, berikut ini diberikan suatu teorema yang menjamin bahwa sebarang modul dapat disisipkan ke dalam suatu modul injektif.

Teorema 6. Setiap modul merupakan submodul dari suatu modul injektif.(Hazewinkelet.al,[3]) Selain modul injektif, juga dikenal adanya modul quasi-injektif, yang merupakan generalisasi dari modul injektif, seperti diberikan dalam definisi berikut ini.

Definisi 7. Diberikan R-modul M. Modul $M$ dinamakan quasi-injektif apabila untuk setiap submodul $A$ dari $M$ dan untuk setiap homomorfisma $f: A \rightarrow M$ terdapat homomor-fisma $g: M \rightarrow M$ sehingga berlaku $\left.g\right|_{A}=f .(\mathrm{Lam},[4])$

Berdasarkan Definisi 7, setiap modul injektif merupakan modul quasi-injektif. Contoh lain dari modul quasi-injektif adalah modul $\mathrm{Z}_{\mathrm{n}}$ atas ring $\mathrm{Z}$.

Selanjutnya, dibahas mengenai modul kontinu dan quasi- kontinu. Pada bagian terdahulu, telah diberikan definisi modul kontinu dan quasi-kontinu. Berikut ini diberikan beberapa sifat yang berkaitan dengan modul kontinu dan quasi-kontinu.

Teorema 8. Diberikan R-modul $M$. Jika $M$ memenuhi aksioma (C2) maka M juga memenuhi aksioma (C3). (Mohammed dan Muller, [5])

Berdasarkan Teorema 7, setiap modul kontinu merupakan modul quasi-kontinu.

Berikut ini diberikan contoh ring, yang apabila dipandang sebagai modul atas dirinya sendiri memenuhi aksioma (C2).

Contoh 9. Jika $R$ ring reguler (Von Newmann) dan $I$ suatu ideal dalam ring $R$, maka $I$ ideal utama yang dibangun oleh suatu elemen idempoten dan merupakan suku jumlah langsung dari $R$. (Lam, [4]) Oleh karena itu, $R$ yang dipandang sebagai modul kanan atas dirinya sendiri memenuhi aksioma (C2).

Berdasarkan Contoh 9, berlaku sifat berikut ini.

Teorema 10. Untuk setiap ring reguler $R$, penyataan-pernyataan di bawah ini ekuivalen.(Lam, [4])

1. $R_{R}$ kontinu.

2. $R_{R}$ quasi-kontinu.

3. $R_{R}$ memenuhi aksioma $(\mathrm{C} 1)$.

Berdasarkan Teorema 10, berikut ini diberikan definisi ring reguler kontinu kanan.

Definisi 11. Suatu ring reguler (von Newmann) dikatakan kontinu kanan apabila memenuhi salah satu dari ekuivalensi pada Teorema10.(Lam, [4])

Lebih lanjut lagi, berikut ini diberikan suatu sifat lain dari modul kontinu.

Lemma 12. Suku jumlah langsung dari suatu modul kontinu juga merupakan modul kontinu.(Sari, [7])

Berikutnya, untuk Teorema 13 sampai 15 , diberikan ring $R, R$-modul $M, S=\operatorname{End}(\mathrm{M}) \mathrm{dan}$ $\Delta=\left\{f \in S \mid \operatorname{Ker}(f) \subseteq^{e} M\right\}$. 
Teorema 13. Jika $R$-modul $M$ kontinu, maka $\Delta$ radikal Jacobson dari ring $S$ dan ring faktor $S / \Delta$ merupakan ring reguler.(Muhamed dan Muller, [5])

Teorema 14. Jika R-modul M quasi-kontinu, maka elemen-elemen idempoten dari ring faktor $S / \Delta$ dapat diangkat menjadi elemen idempoten dari ring S.(Muhamed dan Muller, [5])

Teorema 15. Jika R-modul $M$ kontinu, maka ring faktor $S / \Delta$ merupakan ring kontinu kanan.(Muhamed dan Muller, [5])

Sehubungan dengan ideal suatu ring yang merupakan himpunan bagian dari radikal Jacobson ring tersebut dalam kaitannya dengan elemen-elemen idempoten ring faktornya dan sifat bersih ring faktornya, diberikan sifat berikut ini.

Teorema 16. Diberikan $I$ ideal dari suatu ring $R$ dan $I \subseteq J(R)$ dengan $J(R)$ radikal Jacobson dari ring $R$. Jika ring faktor $R / I$ merupakan ring bersih dan elemen-elemen idempoten dari $R / I$ dapat diangkat menjadi elemen idempoten dari ring $R$, maka ring $R$ merupakan ring bersih.(Han dan Nicholson, [2])

\section{Metode Penelitian}

Penelitian ini merupakan studi literatur. Sebagai tinjauan pustaka dari penelitian ini diberikan sebagai berikut. Definisi dari ring dan elemen bersih diperoleh dari Nicholson (1977) dalam Nicholson dan Zhou[6], sedangkan definisi dan sifat modul injektif, diberikan oleh Hazewinkel et.al.[3].

Selanjutnya, definisi dan beberapa sifat modul kontinu dan quasi-kontinu, termasuk beberapa sifat ring endomorfismanya diperoleh dari Mohamed dan Muller [5].

Sehubungan dengan konsep ring bersih, Han dan Nicholson [2]memberikan suatu syarat cukup suatu ring bersih dalam kaitannya denganring faktor dan elemen-elemen idempoten dari ring faktornya.

Lebih lanjut lagi, Lam [4] memberikan contoh suatu jenis ring yang memenuhi aksioma (C2) dan definisi ring kontinu kanan. Selain itu, Lam [4] juga memberikan sifat elemen idempoten dalam ring endomorfisma dari suatu modul quasi-kontinu, sedangkan beberapa sifat ring endomorfisma dari modul kontinu dan quasi-kontinu lainnya diberikan oleh Camillo et.al.[1]

\section{Hasil dan Pembahasan}

Mengingat definisi modul bersih berkaitan dengan sifat bersih dari ring endomorfisma modul tersebut, maka berikut ini dibahas syarat perlu dan syarat cukup suatu elemen bersih dari suatu ring endomorfisma dari suatu modul.

Teorema 17. Diberikan ring $R, R$-modul $M, S=\operatorname{End}_{R}(M)$ dane, $f \in S$ dengan e suatu endomorfisma idempoten, $A=\operatorname{Ker}(e)$ dan $B=\operatorname{Im}(e)$. Elemen $f$ merupakan elemen bersih jika dan hanya jika $R$-modul $M$ dapat didekomposisikan sebagai $M=A \oplus B=C \oplus D$ dan berlaku $f(A) \subseteq C, \quad(1-f)(B) \subseteq D$ serta $f: A \rightarrow C$ dan $1-f: B \rightarrow D$ keduanya merupakan isomorfisma. (Camilloet.al.,[1])

\section{Bukti:}

$\Leftrightarrow \quad$ Berdasarkan yang diketahui, berlaku $M=A \oplus B$.Karena diasumsikan $f$ suatu elemen bersih, maka terdapat $u \in U(S)$ dan berlaku $f=e+u$. Oleh karena itu dapat dibentuk 
$C=u A \quad$ dan $\quad D=u B, \quad$ sehingga mengakibatkan berlaku $M=C \oplus D$. Karena $A=\operatorname{Ker}(e)=\operatorname{Im}(1-e)$ maka berlaku

$$
f(1-e)=(u+e)(1-e)=u(1-e)
$$

dan karena $B=\operatorname{Im}(e)$, diperoleh

$$
(1-f) e=(e-f e)=-u e
$$

Berdasarkan kesamaan dua fungsi dan karena $u$ unit, maka dari persamaan (1) dan (2) diperoleh $f$ dan $(1-f)$ keduanya merupakan isomorfisma $\operatorname{dan} f(A) \subseteq C$, $(1-f)(B) \subseteq D$.

$(\Leftrightarrow) \quad$ Diketahui terdapat dekomposisi $\mathrm{R}$-modul $M=C \oplus D$, yaitu $C=u A$ dan $D=u B$ dengan $u \in U(S)$ sehingga berlaku $f(A) \subseteq C, \quad(1-f)(B) \subseteq D \operatorname{dan} f: A \rightarrow C$, $1-f: B \rightarrow D$ keduanya merupakan isomorfisma. Oleh karena itu juga berlaku

$$
\begin{aligned}
& f(1-e)=u(1-e) \\
& \Leftrightarrow f-f e=u-u e \\
& \Leftrightarrow f-f e=u+(1-f) e \\
& \Leftrightarrow f-f e=u+e-f e \\
& \Leftrightarrow f=u+e
\end{aligned}
$$

Dengan kata lain $f$ merupakan elemen bersih dalam S. $\square$

Sifat pada Lemma 17 akan digunakan dalam menunjukkan sifat ring endomorfisma dari suatu modul kontinu merupakan ring bersih.

Lebih lanjut lagi, apabila diketahui $R$-modul $M$ quasi-kontinu dan $e^{2}=e \in \operatorname{End}_{R}(W)$ dengan $W$ suatu submodul dari $M$, akan dibahas keberadaan endomorfisma idempotent dalam ring $\operatorname{End}_{R}(M)$

Lemma 18. Diberikan ring $R, R$-modul $M$ dan $S=\operatorname{End}_{R}(M)$. Jika $M$ quasi-kontinu, maka untuk setiap $e^{2}=e \in \operatorname{End}_{R}(W)$ dengan $W$ submodul dari $M$, terdapat $\left(e^{\prime}\right)^{2}=e^{\prime} \in S$ dengan $\left.e^{\prime}\right|_{W}=e .(\operatorname{Lam},[4])$

\section{Bukti:}

Diambil sebarang $e^{2}=e \in \operatorname{End}_{R}(W)$. Diperoleh $W=\operatorname{Ker}(e) \oplus \operatorname{Im}(e)$. Misalkan $\operatorname{Ker}(e)=A$ dan $\operatorname{Im}(e)=B$. Karena submodul $B \subseteq M$, maka terdapat submodul $A^{\prime} \subseteq M$ dengan $A \subseteq A^{\prime} \subseteq M$ sehingga $A^{\prime}$ submodul komplemen dalam $M$. Karena submodul $A^{\prime} \subseteq M$, maka terdapat submodul $B^{\prime} \subseteq M$ dengan $B \subseteq B^{\prime} \subseteq M$ sehingga $B^{\prime}$ submodul komplemen dalam M.Karena $M$ quasi-kontinu, maka berdasarkan (C1) diperoleh $A^{\prime}$ dan $B^{\prime}$ merupakan suku-suku jumlah langsung dari $M$. Karena $B^{\prime}$ memuat $B$ yang komplemen pada $A^{\prime}$ maka $A^{\prime} \cap B^{\prime}=\{0\}$. Oleh karena itu, terdapat submodul $X$ di $M$ sehingga berlaku $M=A^{\prime} \oplus B^{\prime} \oplus X$. Selanjutnya, dibentuk proyeksi $e^{\prime} \in S$ dengan $\operatorname{Im} e^{\prime}=B^{\prime}$ dan $\operatorname{Ker}(e)=A^{\prime} \oplus X$ sehingga $\left.e^{\prime}\right|_{W}=e$.

Berdasarkan Lemma 18 dan mengingat setiap modul quasi-kontinu merupakan modul kontinu, diperoleh sifat seperti dinyatakan dalam lemma berikut ini. 
Lemma 19. Diberikan ring $R, R$-modul $M$ kontinu dengan $W \subseteq M, f \in \mathscr{E n d}_{R}(M)$ dengan $f(W) \subseteq W .\left.J i k a f\right|_{W}-e$ monomorfisma esensial dalam $\operatorname{End}_{R}(W)$ untuk suatu endomorfisma idempoten $e \in \operatorname{End}_{R}(W)$, maka terdapat elemen idempotent $e^{\prime} \in \operatorname{End}_{R}(M)$ dengan $\left.e^{\prime}\right|_{W}=e$ dan $f-e^{\prime}$ suatu unit dalam End $_{R}(M)$. Dengan kata lain $f$ suatu elemen bersih dalam End $_{R}(M)$. (Camilloet.al.,[1])

Selanjutnya, diberikan $R$-modul $M$ dan $f \in \operatorname{End}_{R}(M)$. Kemudian dibentuk himpunan

$$
\varepsilon_{f}=\left\{(W, e)\left|W \subseteq M, f(W) \subseteq W, e^{2}=e \in \operatorname{End}_{R}(W), f\right|_{W}-e \in U\left(\operatorname{End}_{R}(W)\right)\right\}
$$

Himpunan $\varepsilon_{f} \neq \phi$, karena $(0,0) \in \varepsilon_{f}$. Selanjutnya pada himpunan $\varepsilon_{f}$ didefinisikan relasi urutan " $\leq$ ", yaitu untuk setiap $\left(W_{1}, e_{1}\right),\left(W_{2}, e_{2}\right) \in \varepsilon_{f},\left(W_{1}, e_{1}\right) \leq\left(W_{2}, e_{2}\right)$ jika dan hanya jika $W_{1} \subseteq W_{2}$ dan $\left.e_{2}\right|_{W_{1}}=e_{1}$. Berdasarkan Lemma Zorn, himpunan $\varepsilon_{f}$ mempunyai elemen maksimal.

Sehubungan dengan elemen maksimal dari himpunan $\varepsilon_{f}$, berikut ini dibahas suatu sifat elemen maksimal dari himpunan $\varepsilon_{f}$.

Lemma 20. Diberikan ring $R, R$-modul $M, f \in \operatorname{End}_{R}(M)$ dan dibentuk himpunan $\varepsilon_{f}$ seperti pada (3) dengan $(W, e)$ suatu elemen maksima ldalam $\varepsilon_{f}$. Untuk setiap submodul $X \subseteq M$ dengan sifat $X \cap W=0$, berlaku untuk setiap $x \in X, \quad$ jika $f(x) \in W, \quad$ maka $x=0$. (Camilloet.al.,[1])

\section{Bukti:}

Diambil sebarang $x \in X$ dengan $f(x)=w \in W$. Oleh karena itu, $X^{\prime}=x R \subseteq X$. Dari sini diperoleh $w r=f(x) r=f(x r) \in W$. Dengan demikian berlaku

$$
f\left(W \oplus X^{\prime}\right) \subseteq W \oplus X^{\prime} .
$$

Selanjutnya $e$ diperluas ke $X^{\prime}$ dengan mendefinisikan $e x=x$, sehingga

$$
e^{2} x=e(e x)=e x,
$$

yang berarti $e^{2}=e \in \operatorname{End}_{R}\left(W \oplus X^{\prime}\right)$. Karena $(f-e) W=W$, maka untuk $w \in W$ terdapat $w_{1} \in W$ sehingga $(f-e) w_{1}=w$. Oleh karena itu diperoleh

$$
(f-e)\left(w_{1}+w_{1}-x\right)=w+x \text {. }
$$

Hal ini berarti $f-e \in \operatorname{End}_{R}\left(W \oplus X^{\prime}\right)$ surjektif. Lebih lanjut lagi, diambil sebarang $m \in \operatorname{Ker}(f-e) \subseteq W \oplus X^{\prime}$. Diperoleh $m=w^{\prime}+x r$ untuk suatu $w^{\prime} \in W$ dan $x r \in X^{\prime}$ serta berlaku

$$
\begin{aligned}
& (f-e)\left(w^{\prime}+x r\right)=0 \\
& \Leftrightarrow(f-e) w^{\prime}+f x r-e x r=0 \\
& \Leftrightarrow(f-e) w^{\prime}+w r=x r \in W \cap X^{\prime}=0
\end{aligned}
$$

Karena $x r=0$, maka $f x r=w r=0$, sehingga $(f-e) w^{\prime}=0$, yang mengakibatkan $w^{\prime}=0$. Dengan demikian $f-e \in \operatorname{End}_{R}\left(W \oplus X^{\prime}\right)$ injektif. Jadi $f-e \in \operatorname{End}_{R}\left(W \oplus X^{\prime}\right)$ suatu unit. Dari sini diperoleh $\left(W \oplus X^{\prime}, e\right) \in \varepsilon_{f}$. Kontradiksi dengan $(W, e)$ maksimal dalam $\varepsilon_{f}$. Oleh karena itu $\left(W \oplus X^{\prime}, e\right)=(W, e)$. Hal ini berarti $X^{\prime}=0$, yang mengakibatkan $x=0$. 
Sehubungan dengan masalah elemen maksimal dari himpunan $\varepsilon_{f}$, berikut ini diberikan suatu sifat untuk kasus $R$-modul $M$ kontinu nonsingular atau semisederhana.

Teorema 21. Diberikan $R$-modul $M$ semisederhana atau kontinu non singular, $f \in \operatorname{End}_{R}(M)$ dan $(W, e) \in \varepsilon_{f}$ seperti pada (3)

a. $\quad(W, e)$ maksimal jika dan hanya jika $W=M$.

b. Untuk sebarang $\left(W_{\left.0, e_{0}\right)} \in \mathcal{E}_{f}, f=e+u\right.$ dengan $e^{2}=e$ di $\operatorname{End}_{R}(M)$ perluasan dari eodan $u$ Bukti: unit di $\operatorname{End}_{R}(M)$. Khususnya, M merupakan modul bersih.(Camilloet.al.,[1])

(a) $(\Leftarrow)$ Diketahui $W=M$. Trivial.

$\Leftrightarrow$ Diberikan $(W, e)$ maksimal dalam $\varepsilon$.

Dalam hal ini, pembuktian dilakukan dalam 3 langkah, sebagai berikut.

Langkah 1

Akan ditunjukkan $W$ suku jumlah langsung dari $M$. Untuk kasus $M$ semisederhana, trivial. Oleh karena itu berikut akan dibahas untuk $M$ kontinu dan nonsingular. Andaikan $W$ bukan submodul tertutup, maka terdapat perluasan esensial maksimal (closure) dari $W$, namakan $E$, sehingga $W \subseteq e$. Berdasarkan (C1), terdapat $X \subseteq M$ sehingga berlaku $M=E \oplus X$. Selanjutnya, diambil sebarang $y \in E$, kemudian dibentuk $I=\{r \in R \mid y r \in W\}$.Diambil sebarang $r_{1}, r_{2} \in I, r^{\prime} \in R$, maka $y r_{1}, y r_{2} \in W$, dan diperoleh

a. $r_{1}-r_{2} \in I$, karena $y r_{1}-y r_{2}=y\left(r_{1}-r_{2}\right) \in W$.

b. $r_{1} r^{\prime} \in I$, karena $y r_{1} r^{\prime} \in W$

Dengan demikian, $I$ ideal kanan dari ring $R$.

Berikutnya, diambil sebarang $0 \neq m \in E$. Karena $W \subseteq E$, maka terdapat $r \in R$ sehingga berlaku $0 \neq m r \in W$. Selanjutnya, diambil sebarang $0 \neq r^{\prime \prime} \in R$. Karena $W \subseteq M, M$ nonsingular, $0 \neq m r \in W$ dan $0 \neq r^{\prime \prime} \in R$, maka $0 \neq m r r^{\prime \prime} \in W$. Oleh karena itu, $0 \neq r r^{\prime \prime} \in I$. Dengan demikian diperoleh $I \subseteq^{e} R_{R}$

Lebih lanjut lagi, karenay $\in E$, maka $f(y) \in f(E)$. Karena $f \in E n d_{R}(M)$ dan $E \subseteq M=E \oplus X$, maka terdapat $z \in E$ dan $x \in X$ sehingga $f(y)=z+x$. Untuk setiap $r \in I$, berlaku $f(y) r=z r+x r \in W \subseteq E$ dan $z r \in E$, sehingga $x r=f y r-z r \in E$. Karena $x r \in X$, maka $x r \in E \cap X=\{0\}$. Hal ini berarti $r \in \operatorname{ann}_{R}(x)$. Dengan demikian berlaku

$$
I \subseteq \operatorname{ann}_{R}(x) .
$$

Berdasarkan (4) dan (5), diperoleh $\operatorname{ann}_{R}(x) \subseteq{ }^{e} R_{R}$. Lebih lanjut lagi, karena $R$-modul $M$ nonsingular, maka $x=0$, sehingga $f(y)=z \in E$. Jadi $f(E) \subseteq E$.

Berikutnya, berdasarkan Lemma 12, karena $E$ suku jumlah langsung dari $M$ dan $M$ kontinu, maka $E$ kontinu. Karena $E$ kontinu, maka berdasarkan Lemma 18, terdapat $\left(e^{\prime}\right)^{2}=$ $e$ di $\operatorname{End}_{R}(E)$ dengan sifat $\left.e^{\prime}\right|_{W}=\left.e \operatorname{dan} f\right|_{E}-e^{\prime}$ unit di $E n d_{R}(E)$. Dengan demikian $\left(E, e^{\prime}\right) \in \varepsilon_{f}$ dan $(W, e) \leq\left(E, e^{\prime}\right)$. Kontradiksi dengan $(W, e)$ elemen maksimal. Jadi seharusnya $W$ tertutup, yang berarti $W=E$. Dari sini, diperoleh $W$ suatu suku jumlah langsung dari $M$. Sekarang dilanjutkan ke langkah 2.

Langkah 2

Akan ditunjukkan $W=M$.

Di sini, hanya diasumsikan bahwa $R$-modul $M$ kontinu. Dari langkah 1 , diperoleh $M=W \oplus X$. Andaikan $X \neq 0$. Karena $(W, e)$ elemen maksimal di $\varepsilon_{f}, X \subseteq M$ dan $W \cap X=\{0\}$, maka berdasarkan Lemma 20, berlaku untuk setiap $x \in X$, jika $f(x) \in W$ 
maka $x=0$. Selanjutnya, diambil sebarang $x_{1}, x_{2} \in X$ dengan $f\left(x_{1}\right)=f\left(x_{2}\right)$. Dari sini diperoleh

$$
f\left(x_{1}\right)-f\left(x_{2}\right)=f\left(x_{1}-x_{2}\right)=0 \in W . \quad \text { Berdasarkan Lemma 20, berlaku }
$$

$x_{1}-x_{2}=0 \Leftrightarrow x_{1}=x_{2}$ Dengan demikian $\left.f\right|_{X}$ suatu monomorfisma. Oleh karena itu diperoleh $X \cong f(X)$. Dari sini juga diperoleh $W \cap f X=\{0\}$. Oleh karena itu berlaku $W \oplus f X=M$. Lebih lanjut lagi, misalkan $A=\operatorname{Ker}(e)$ dan $B=\operatorname{Im}(e)$. Karena endomorfisma $f$ suatu elemen bersih di $\operatorname{End}_{R}(W)$, berdasarkan Teorema 17, terdapat $R$-modul $W$ yang dapat didekomposisikan menjadi $W=A \oplus B=C \oplus D$ serta memenuhi $f A \subseteq C$, $(1-f)(B) \subseteq D$ dan $f: A \rightarrow C, 1-f: B \rightarrow D$ keduanya merupakan isomorfisma. Dengan demikian, diperoleh $f: A \oplus X \rightarrow C \oplus f X$ suatu isomorfisma, sehingga

$$
M=W \oplus X=(C \oplus f X) \oplus D
$$

Selanjutnya, didefinisikan homomorfisma $e^{*}$, proyeksi dari $M$ pada $B$ dengan

$\operatorname{Ker}\left(e^{*}\right)=A \oplus X$.

Berdasarkan Teorema 17, endomorfisma $f$ merupakan elemen bersih di $\operatorname{End}_{R}(M)$. Dengan demikian diperoleh $\left(M, e^{*}\right) \in \varepsilon_{f}$ dan $(W, e) \leq\left(M, e^{*}\right)$. Kontradiksi. Oleh karena itu seharusnya $X=0$, dan akibatnya $W=M$. $\square$

b. Diambil sebarang $\left(W_{0}, e_{0}\right) \in \varepsilon_{f}$, berdasarkan bagian a terdapat elemen maksimal dari $\varepsilon_{f}$, yaitu $(M, e) \in \varepsilon_{f}$ dan $f=e+u$ dengan $u$ elemen unit di $\operatorname{End}_{R}(M)$. Oleh karena itu modul $M$ bersih.

Berdasarkan Teorema 21, berikut ini diberikan suatu sifat dari modul kontinu lainnya.

Teorema 22. Setiap modul kontinu merupakan modul bersih. (Camilloet.al.,[1])

\section{Bukti:}

Diberikan $\quad R$-modul $M$ kontinu, $S=\operatorname{End}_{R}(M)$ dan $\quad \Delta=\left\{f \in S \mid \operatorname{Ker}(f) \subseteq^{e} M\right\}$. Berdasarkan Teorema 13, diperoleh ring faktor $T=S / \Delta$ merupakan ring reguler dan $\Delta$ merupakan radikal Jacobson dari $S$ Oleh karena itu, modul $T_{T}$ non singular dan berdasarkan Teorema 15, $T_{T}$ kontinu. Berdasarkan Teorema 21 diperoleh $T \cong \operatorname{End}_{T}(T)$ merupakan ring bersih. Selanjutnya, karena modul $M$ kontinu mengimplikasikan modul $M$ quasi-kontinu, maka berdasarkan Teorema 14 berlaku elemen-elemen idempoten dari ring faktor $T$ dapat diangkat menjadi elemen-elemen idempoten dari ring $S$. Oleh karena itu, berdasarkan Teorema 16, ring $S$ merupakan ring bersih. Jadi $R$ - modul $M$ merupakan modul bersih. $\square$

Lebih lanjut lagi, karena setiap modul quasi-injektif merupakan modul kontinu, maka setiap modul quasi-injektif merupakan modul bersih. Karena setiap modul injektif merupakan modul quasi-injektif, maka setiap modul injektif merupakan modul bersih. Oleh karena itu berdasarkan Teorema 22, diperoleh akibat-akibat langsung berikut ini.

Akibat 23. Ring $\mathrm{Z}_{n}$ merupakan ring bersih.(Sari, [7])

\section{Bukti:}

Diperhatikan bahwa modul $\mathrm{Z}_{\mathrm{n}}$ atas dirinya sendiri merupakan modul injektif yang juga merupakan modul kontinu. Oleh karena itu, berdasarkan Teorema $22, \mathrm{Z}_{\mathrm{n}}$-modul $\mathrm{Z}_{\mathrm{n}}$ merupakan modul bersih. Akibatnya ring $\operatorname{End}_{\mathrm{Z}_{n}}\left(\mathrm{Z}_{n}\right)$ merupakan ring bersih. Di lain pihak, berlaku $Z_{n} \cong \operatorname{End}_{\mathrm{Z}_{n}}\left(\mathrm{Z}_{n}\right)$. Dari sini diperoleh ring $\mathrm{Z}_{\mathrm{n}}$ merupakan ring bersih.

Akibat 24. Setiap modul dapat disisipkan sebagai submodul ke dalam suatu modul bersih. 


\section{Bukti:}

Diberikan sebarang $R$-modul $M$, berdasarkan Teorema 3, $R$-modul $M$ dapat disisipkan ke dalam suatu modul injektif sebagai submodul. Karena setiap modul injektif merupakan modul kontinu yang merupakan modul bersih, maka $R$-modul $M$ submodul dari suatu modul bersih. $\square$

Akibat 24 juga meyiratkan bahwa untuk setiap modul, baik modul bersih ataupun bukan modul bersih, selalu dapat dikonstruksikan suatu modul bersih yang memuatnya sebagai submodul. Hal ini bersesuaian fenomena bahwa $\operatorname{End}_{\mathrm{Z}}(\mathrm{Z}) \cong \mathrm{Z}$ yang bukan merupakan ring bersih termuat dalam $\operatorname{End}_{z}(Q) \cong Q$ yang merupakan ring bersih. Dengan kata lain modul Z sebagai Zmodul yang bukan modul bersih termuat dalam Z-modul Q yang merupakan modul bersih.

\section{Simpulan}

Berdasarkan sifat bahwa setiap modul merupakan submodul dari suatu modul injektif dan setiap modul kontinu merupakan modul bersih, diperoleh bahwa setiap modul merupakan submodul dari suatu modul bersih.

\section{Ucapan Terima Kasih}

Artikel ini merupakan bagian dan hasil dari tesis penulis pertama, yang pembahasannya dilakukan dengan cara yang sedikit berbeda dari tesis. Oleh karena itu, atas terselesaikannya artikel ini, penulis ucapkan terima kasih kepada Ibu Indah Emilia Wijayanti selaku pembimbing.

\section{Daftar Pustaka}

1. Camillo, V. P., Khurana, D., Lam, T.Y., Nicholson, W. K., dan Zhou, Y. 2006. Continous Modules are Cleans. J Algebra 304, halaman 94-111.

2. Han, J. dan Nicholson,, W. K. 2001. Extensions of Clean Rings. Communicationsion Algebra, 29(6), halaman $2589-2595$.

3. Hazewinkel, M., Gubareni, N., dan Kirichenko, V. V. 2004. Algebras, Rings, and Modules. Kluwer, Academic Publishers, New York.

4. Lam, T. Y. 1998. Lectures on Modules and Rings. Graduate Texts in Mathematics No. 189, Berlin, New York: Springer-Verlag.

5. Mohamed, Saad H dan Muller, Bruno J. 1990. Continuous and Discrete Modules, Cambridge University Press, New York.

6. Nicholson, Keith W dan Zhou, Yiqiang, 2004. Clean Rings: A Survey.Advanced in Ring Theory, halaman 181-198.

7. Sari, Kartika. 2012. Penyisipan Sebarang Ring ke dalam Suatu Ring Bersih. Tesis. Yogyakarta: FMIPA Universitas Gajah Mada. 
Sari \& Wijayanti/ JMI Vol 11 No 1 April 2015, Pp. 65 - 74 